\title{
Theoretical Analysis of Traffic Organization and Evaluation System of Highway Passenger Transport Hubs in Small Town
}

\author{
Ting YU ${ }^{1, \text { a }}$,Jian-Xiao MA ${ }^{2, b}$, Ya-Yun ZHU ${ }^{3, c}$ and Yang LIU ${ }^{4, d}$ \\ 1,2,3,4 Nanjing Forestry University; Nanjing Jiangsu 210037,China \\ a1026387911@qq.com, bjxma@163.com, '531411012@qq.com, d1031407319@qq.com
}

\begin{abstract}
Keywords: Small Town; Highway Passenger Transport Hub; Traffic Organization; Rationality; Index Abstract. With the development of urban economy, highway passenger transport hubs as the internal and external communication bridge between cities, become more and more important. The traffic organization directly impacts the efficiency of the hub. This paper analysed the present situation of traffic organization of highway passenger transport hubs and pointed out the main causes of low efficiency. According to the actuality of traffic organization, this paper put forward the new design ideas and principles of traffic organization in small towns. Then, the research stated the specific content of traffic organization, including hubs' internal traffic organization, external traffic organization, internal-external traffic organization, and put forward the evaluation system of traffic organization of town highway passenger transport hub. This research provides the reference for the same type of traffic organization design of highway passenger transport hub in small town.
\end{abstract}

\section{Introduction}

With the acceleration of urbanization, the support of national policy, links between the big cities and small and medium-sized cities, and between cities and towns, and between villages and towns have become more closely. Town passenger transport hub is as a link between big cities and small and medium-sized cities. The city's passenger transport system is the most complicated part in urban traffic[1].Highway passenger transport hubs are the most prominent part of contradictions and problems. But passenger transport hub is often the weak part in the process of the traffic system, such as poor organization of means of transportation, unreasonable passenger guidance system, these problem are easy to lead to confusion. At present, the study of hub planning started relatively late, the research of passenger transport hub which focused more on big cities than small towns. The researches of urban passenger transport hub are more about optimization method of hubs' layout, the forecasting method of hubs, the evaluation method of hub layout, hub operations and system construction. However, the researches of passenger traffic organization and evaluation system are less[2-5]. Under the background of new pattern urbanization, this paper mainly studied traffic organization and evaluation system of the highway passenger transport hub. This will help to make the highway passenger transport hub become efficient.

\section{Present Situation of Traffic Organization in Highway Passenger Transport Hubs}

Highway passenger transport hub is aggregation of urban road passenger transportation facilities and equipment[6]. Urban internal and external traffic is the root causes of formation and development of passenger transport hubs in small town. Because of the imperfect urban transportation and weak infrastructure, it leads to irrationality of facility layout and poor coordination of traffic organization. The main performance is as follows:

(1)Various modes of transportation is not closely connected. At present, a lot of town highway passenger transport hubs are plane layout, all sorts of modes of transportation are located on the same plane, it may need too large space occupation. If there're no transfer channels, people may take a long time to transfer, which increases people's travel cost and travel time. Besides, it results in disorderly streamlines, traffic organization confusion and transfer inconvenience. Unlike urban highway passenger transport hub, passenger of town highway passenger transport hub mainly arrived by private cars, bus, motorcycles and non-motor vehicles, taxi undertakes a small amount of traffic. 
But at present, the main consideration of the construction of passenger transport hub is motor vehicle flow and passengers, and the non-motor vehicles and motorcycles are given less consideration.

(2)The proportion of public transport is low and the distribution is not uniform. Due to economic and policy reasons, towns failed to implement the bus priority policy, the passengers can't be quickly evacuated.

(3)The road passenger transport station facilities are not complete, and service capabilities need to be improved. Town's transport infrastructure is relatively backward, the proportion of parking spaces for motor vehicles and non-motor vehicle is unreasonable, and the utilization rate of special driveway is low. Transfer line is not clear, town highway passenger transport hub is lack of corresponding pedestrian crossing facilities.

\section{Ideas and Principles for the Design of Traffic Organization}

Design Thinking. The traffic organization design should be based on the layout scheme of town highway passenger transport hub, planners take the characteristics of demand diversity and more hierarchical service form of highway passenger transportation into consideration when they give a scheme of traffic organization[7].The next step is to use evaluation system to assess the rationality of the scheme. A perfect scheme needs to be continuously optimized. With the continuous adjustment of the traffic organization, the interaction between town and the highway passenger transport hub will be fully developed, which promotes the further development of the town.

Design Principles. (1)Smooth traffic, seamless connection. Reasonable layout of people and vehicles ensures the efficient operation of the transport system. At the same time, it can shorten the passenger transfer distance, reduce the time of retention in the hub, avoid the occurrence of retention and overcrowding. (2)People-oriented, public transport priority. According to the characteristics of town passenger flow, people who use public transportation in and out of the station is the main part of the passenger flow[8].Town traffic should be dominated by bus priority and arrange the structure of various modes of transportation reasonably.(3)Avoid crossing. The ultimate goal of the highway passenger transport hub is to realize the rapid distribution of passenger flow. Making passenger hub to be efficient and fast is equivalent to make sure that people, traffic flow and non-motor vehicle will not interfere with each other. (4)Control land, fully use the space. The highway passenger transport hub is developing in the direction with multi-level and multi-way, and the traffic organization is gradually transiting from the plane to the three-dimensional. (5)Ensure the realization of functional integration. With the reasonable traffic organization of the hub, fully integrating the existing resources, passenger transport hubs maximum possibly play function to improve the efficiency of the whole hub system.

\section{Traffic Organization Design}

The traffic facilities of the travel, the transfer vehicle and the transportation facilities are the basic elements of the traffic organization of the highway passenger transport hub[9].It is an important content of the whole project to design the reasonable planning of the relationship among the travel, the transfer vehicle and the transportation facilities. Whether the traffic organization is reasonable or not directly affects the overall function of the hub, and the traffic network is closely related to the operation of the hub, and even related to the development of the city.

Traffic organization design of town highway passenger transport hub mostly contains 3 parts, including the internal traffic organization, the external traffic organization and the internal-external traffic organization [10].

The Internal Traffic Organization. The internal traffic organization is to realize the rapidly transfer of the passenger in the hub by means of designing the reasonable organization of people and traffic flow. Highway passenger transport hub converges many means of transportation, including the private car, motorcycle, public transport, bicycles, taxis, walking and other modes of transportation. 
Taking these factors into consideration, the content of internal traffic organization covers two important parts: pedestrian organization and vehicle organization.

Passengers are the main participants in the hub, the feeling of comfort and convenience of passengers are the best embodiment of hub's function efficiency. Passenger flow has multiple characteristics: 1) People arrive or leave the station with different purpose, using different modes of transportation and different directions, the flow of passenger is random and multi-directional .2) Because of the different behavior of the tourists, people and traffic flow interference with each other, passenger flow has the characteristic of mixture.3) Affected by the factors such as the seasons, weather, holidays and so on, the passenger flow is fickle and also has agglomeration effect in some period of time[11]. Passengers have a number of characteristics so the hub station needs to be equipped with complete signs, suitable dedicated channels, and clear pedestrian space.

Personnel who design the station should clear the car line combining with the hub's structure and function, and management personnel should arrange car trips reasonably, timely and effectively evacuate passengers based on the characteristics of passenger. Roads which are connected with station have more traffic volume, they need to be paid more attention to traffic grooming, avoiding congestion. Strictly distinguish between traffic flow lines so that the flows can' t interference with each other.

The External Traffic Organization. The external traffic organization is to make traffic flow into the main road quickly and efficiently by appropriate traffic organization which combines the external environment of the station. The external traffic organization must include these points: (1) Multi-channel evacuation; (2)High grade road evacuation; (3)Reduce crossing traffic; (4) Balance the traffic loading of intersection near the hub[12].

In order to achieve the purpose of fast out of town, hub must be linked up with higher grades of roads. One side of the station should look towards the main roads, the vehicle can be quickly out of the city. The regional road network around the hub converges with the hub through reasonable traffic organization, making the larger traffic flow evacuate the road network quickly, improving the overall service level and transfer efficiency.

Highway passenger transport hub as the main foreign exchange area, is the core area of the traffic. There is a considerable scale of crossing traffic, so it is important to arrange road grade around the hub reasonably. Making the vehicle as far as possible go across the periphery of the core region and reducing non-essential crossing to improve efficiency of vehicles in and out of the town. Besides, we can set some traffic signs to reminder the vehicle which need to pass by the area of highway passenger transport hub to choose other sections. Meanwhile, timely ease traffic congestion by adjusting the signal timing.

The Internal-external Traffic Organization. The internal-external traffic organization is to make internal traffic stream match service ability of external road network by adjusting entrances and exits of the settings.

Set up multiple entrances and exits separately and ensure that vehicle right into and right out of the hub to improve the safety index. Entrances can be set in secondary trunk road or branches. The vehicles which are in and out of highway passenger transport hub are mainly large vehicles. Large vehicles in and out of the station need a gradual acceleration and deceleration process, they need more time in the process of preparation. So main roads can't be connected with the hub, otherwise, it's easy to affect the urban traffic and increase urban traffic pressure.

\section{Evaluation System}

On the basis of the layout of hub facilities, traffic organization can have a variety of schemes, but how to weigh the pros and cons of each organization plan, we need to develop a set of reasonable and effective evaluation system. Referring to the traffic organization of urban comprehensive passenger hub, select the main factors of the traffic organization which can reflect vehicle organization coordination and satisfaction of the customers. According to the relationship between the indicators, 
the overall structure of the index system is divided into three layers, including the target layer, the criterion layer and the index layer [13].

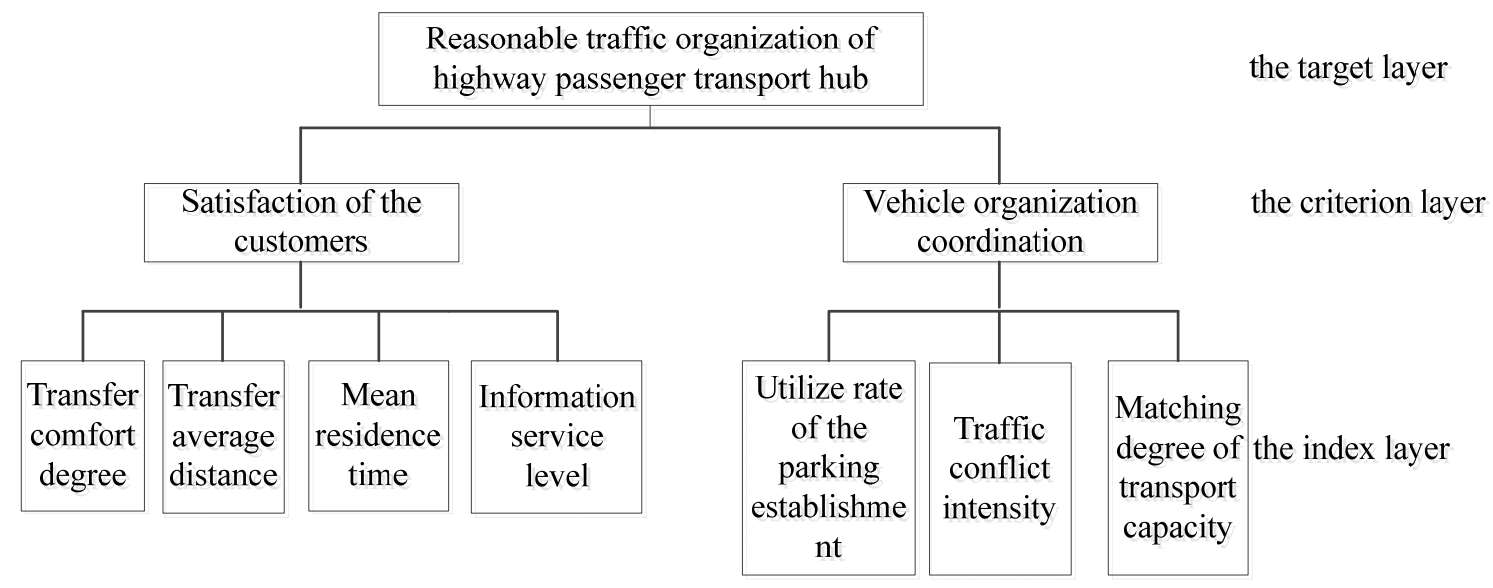

Fig.1 Evaluation index system

Evaluation indexes of the customers' satisfaction.(1)Transfer comfort degree( $T$ ).It means the comfort and satisfaction of the passengers can be get from the services provided by the hub. It reflects the level of service provided by the hub for passengers.

$$
T=\beta_{1} k_{1}+\beta_{2} k_{2}+\beta_{3} k_{3}
$$

Of which, $\beta_{1}, \beta_{2}, \beta_{3}$ are the service level coefficients for passenger transport hub, and

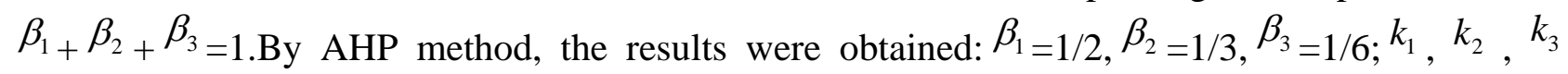
represents the situation of signs, cover facilities and whether the hub provides a seat or automatic transport equipment.

Tab.1 Value table for different service level

\begin{tabular}{|c|c|c|c|c|}
\hline equipment condition & lack & imperfection & good & perfect \\
\hline signs condition $k_{1}$ & $0 \sim 2$ & $2 \sim 5$ & $5 \sim 7$ & $7 \sim 9$ \\
\hline cover facilities condition $k_{2}$ & $0 \sim 3$ & $3 \sim 6$ & $6 \sim 8$ & $8 \sim 9$ \\
\hline equipment condition $k_{3}$ & $0 \sim 4$ & $4 \sim 6$ & $6 \sim 8$ & $8 \sim 9$ \\
\hline
\end{tabular}

(2)Transfer average distance $(L)$ ).For the whole passenger transport hub, the average walking distance is an important index for the convenience and efficiency of the transfer organization. The average transfer distance is small, the operation efficiency of the whole transport hub is high, vice versa. Using different traffic modes results in different transfer volume.

$$
L=\sum M_{i j} \times L_{i j} / M_{\text {换乘 }}
$$

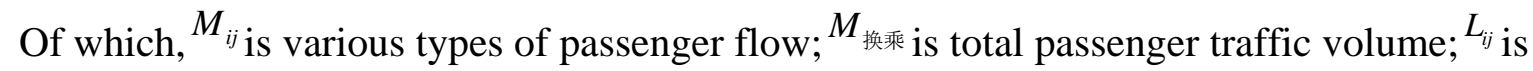
walking distance of all types of interchange passengers. In addition, taking into account the difference between horizontal and vertical walking distance (go upstairs/downstairs ) of mental and physical exertion. Let $L_{i j}=H_{i j}+K \times V_{i j}$, of which, ${ }^{H i j}$ is horizontal distance, ${ }^{i j}$ is difference of 
elevation, $K$ is distance increasing coefficient. When going upstairs, value of $K$ is 4.0, when going downstairs, value of $K$ is 2.0. (If choosing the escalator, value of $K$ is 1.0).

(3)Mean residence time ( $\bar{T}$ ).It reflects the traffic organization level of highway passenger transport hub, as well as the timeliness of the evacuation of the hub, and it is also the most important indicator of the organization's scheme.

$$
\bar{T}=\sum_{i=1}^{n} \sum_{j=1}^{n} Q_{i j} \bullet t_{i j} / \sum_{i=1}^{n} \sum_{j=1}^{n} Q_{i j}
$$

Of which, ${ }{ }_{i j}$ is the passenger flow volume produced in the process when people choose traffic mode $i$ changing to $j{ }^{t_{i j}}$ is the time people need in the process when people choose traffic mode $i$ changing to $j$.

(4)Information service level ( $I$ ).It means the level of satisfaction about the information for guiding passengers in the passenger transport hub. Because the degree of information service is difficult to be reflected by quantitative index, therefore, the rank method is used to demarcate it.

$\mathrm{I}=\{$ excellent, good, ordinary, poorer, bad $\}$

Evaluation indexes of vehicle organization. (1)Utilize rate of the parking establishment( $U$ ).It reflects the comfort level of park-and-ride in the passenger transport hub.

$$
U=Q \gamma_{b} T / P \beta
$$

Of which, ${ }^{Q}$ is passenger volume in peak hours. ${ }^{\gamma}{ }_{b}$ is the proportion of people who use park-and-ride. $P$ is the number of parking space in passenger transport hub. $T$ is average parking time. $\beta$ is the proportion of the vehicle of park-and-ride.

(2)Traffic conflict intensity $(C$ ).It reflects the organization level of passenger transport hub and the safety level of passenger, it also measures the capacity coordination of the different traffic modes. It can be used to judge the adaptability of passenger transport transfer equipment.

$$
C=P_{c} / S
$$

Of which, $P_{c}$ is the number of conflict points of different traffic flow in the hub; $S$ is the operating area of hub.

(3)Matching degree of transport capacity ( $M$ ).It reflects the coordination between different traffic modes' capacity, and can be used to judge adaptability of convergence between various transport equipment.

$$
M=\frac{E}{\sum_{k=1}^{n} p_{k} \bullet \alpha_{k}}
$$

Of which, $E$ is passenger flow volume in the peak time, $p_{k}$ is passenger transport capacity of the traffic mode $k$ in passenger transport hub, $a_{k}$ is the proportion of choosing the traffic mode $k$ (\%).Matching degree of transport capacity index is the characterization of the relationship of different passenger transportation's supply and demand, and it is related to the transport characteristics of connected traffic modes. When $M \leq 1$, it means the case of connection of traffic mode is good, otherwise, the case is bad.

\section{Conclusion}

Town highway passenger transport hub as a gateway to converge internal and external areas, the rationality of its traffic organization directly affects the efficiency of the hub. With the development 
of the town, the traffic infrastructure of the highway passenger transportation hub has been improved, the traffic organization scheme of passenger transport hub should also be changed on the basis of the result of evaluating indexes. Establishing a continuous and safe transfer system needs to ordinate the road grades, improve the supporting facilities, so it can give full play to the function of the hub station.

\section{Acknowledgements}

This work is supported by the research on the connecting mode of urban highway passenger transport hub in the new urbanization background (KYLX15_0915).

\section{References}

[1] Zhou Peidong. Layout planning of township highway passenger station based on urbanization [D]. Guangxi University, 2014.

[2] Tang Mingtan,Song Jinsong,etal.Overview of development and planning of small towns[M].Beijing: China Building Industry Press, 2004:7.

[3] Gao Hongbo. Extraction of passenger hub traffic organization research[J].Wireless Technology,2014(2):154-154.

[4] Qi Kai. Research on optimization for flow routing of urban passenger hubs [D]. Beijing Jiaotong University, 2012.

[5] Fan Lu. Study on transportation organization of the comprehensive passenger transportation hub[D]. Xi'an: Chang'an University, 2010.

[6] Niu Yanli.Highway passenger transport hub transfer efficiency countermeasures[D].Chongqing University,2013:23-26.

[7] Fan Jun,Guo Xiucheng,Song Changjuan,et al. The Research on the planning of highway passengers transfer terminal in the small town [C]// the 21th Annual Meeting and Academic Seminar of China's Urban Transportation Planning Academic Committee in 2005.2005:429-434.

[8] Luo Mi. Study on the traffic organization optimization design of city's highway passenger transport hub based on the post occupancy evaluation[D]. Chongqing University,2004: 36-42.

[9] Zong Ting. Study of passenger transport hub traffic organization based on many kinds of traffic ways[D]. Chang'an University,2008:7-49.

[10] Chen Fanghong,Wang Qingyu,Luo Xia,et al. Research of large comprehensive passenger transport hub’s traffic organization[J]. Railway Transport and Economy, 2008, 30(3): 61-64.

[11] Dai Juanli. Study on site-selection and traffic transfer of highway passenger terminal in developed small town. Chang'an University, 2012:7-48.

[12] Huang Hainan,Guo Xiucheng,Fan Jun,et al. Study on local area traffic organization under influence of expressway passenger transport junction[J]. Technology of Highway and Transport, 2008 (1): 118-120.

[13] Zhou Wei, Jiang Cailiang. Theoretical analysis of the interchange passengers in urban transport terminals[J]. Transportation System Engineering and Information, 2005, fifth (5): 23-30. 